\title{
LA CESIÓN DE PATRONATO: UNA ESTRATEGIA FAMILIAR EN LA EMANCIPACIÓN DE ESCLAVOS EN CUBA. 1870-1880*
}

\author{
Aisnara Perera Díaz \\ Maria de los Ángeles Meriño Fuentes \\ Miembros del Seminario Permanente Hispano-Cubano de Familia, Identidad \\ Cultural y Cambio Social adjunto al Centro de Investigación y Desarrollo de la \\ Cultura Cubana "Juan Marinello", Ciudad de La Habana, Cuba.
}

\begin{abstract}
Resumo
O artigo é dedicado ao estudo dos efeitos imediatos da Lei Moret, ou do Ventre Livre, sobre a vivência das famílias escravas cubanas. Com base em um tipo sui generis de escritura notarial, as chamadas cessões de patronato (cesiones de patronato), as autoras estabelecem as relações entre as estratégias familiares utilizadas a favor das crianças declaradas formalmente livres e o conhecimento das práticas legais formais por parte dos escravos.
\end{abstract}

\section{Pallavras-Chave}

Escravidão • Família • Lei Moret ou do Ventre Livre • Cuba

\section{Abstract}

This article studies the immediate effects of the Moret Law, also known as Free-Womb Law, on Cuban slave families. Exploring a unique type of notarial record, the cesiones de patronato (transfer of authority over apprentices), the authors establish the relationship between family strategies involving children who were declared free and the slaves' familiarity with formal legal practices.

\section{Keywords}

Slavery $\bullet$ Family $\bullet$ Moret Law $\bullet$ Cuba

\footnotetext{
*Agradecemos al profesor Robert W. Slenes de la Universidad Estatal de Campinas, Estado de São Paulo, Brasil, sus valiosos comentarios y sugerencias realizados durante el Seminario Internacional "Hacer hablar el documento una práctica historiográfica en la historia de la esclavitud y la cultura de Cuba y Brasil" coordinado por la profesora Rebecca J. Scott y realizado del 5 al 27 de febrero del 2005 en el Centro de Investigación y Desarrollo de la Cultura Cubana Juan Marinello La Habana, Cuba.
} 
La historiografía cubana sobre la esclavitud producida desde la década del 80 del siglo XX muestra cierta ausencia de matices cuando examina el proceso abolicionista y dentro de este la llamada Ley Moret o de Vientres Libres de $1870 .{ }^{1}$ Unánimemente se descalifica a la misma por no eliminar de golpe el ominoso sistema a la vez que se le considera una continuación encubierta de la esclavitud. Por otro lado al analizar críticamente su articulado se recurre a los reparos provenientes de la Sociedad Abolicionista Española, ${ }^{2}$ aunque acertadamente se pone en evidencia el alcance político de la legislación en tanto le restaba fuerza a la iniciativa emancipadora de la revolución independentista iniciada el 10 de octubre de 1868 por Carlos Manuel de Céspedes ofreciéndole, precisamente, la libertad a sus esclavos e incorporándolos al movimiento. ${ }^{3}$

Es común leer en los textos citados que la ley no se cumplía pero, además del énfasis en las falsificaciones de las edades de los adultos de más de 60 años o cercanos a ella, no se revela qué otros aspectos de la misma fueron violados, mientras que para apoyar la idea de su alcance limitado se insiste sólo en las ventajas que la ley le concedía a los dueños, como por ejemplo

\footnotetext{
${ }^{1}$ Nos referimos sobre todo a un grupo de textos publicados a raíz del centenario de la abolición de la esclavitud como una colección de artículos de varios investigadores editado bajo el titulo de La esclavitud en Cuba. La Habana: Editorial Academia, 1986. Burguesía esclavista y abolición. La Habana: Editorial de Ciencias Sociales, 1987, de María del Carmen Barcia Zequeira, y la compilación de documentos brevemente comentados por Torres Cuevas, Eduardo y Eusebio Reyes. Esclavitud y sociedad. Notas y documentos para la historia de la esclavitud negra en Cuba. La Habana: Editorial de Ciencias Sociales, 1986.

${ }^{2}$ Sólo desde Madrid era posible que se lanzaran generalizaciones como estas "los esclavos mayoritariamente no tienen partidas de bautismo y era fácil sustituir las verdaderas por otras falsas", este era el tono de las denuncias aparecidas en la prensa abolicionistas madrileña recogidas por Barcia. Ob. Cit. P 143, el calor de un debate de índole político es propicio para que se hagan afirmaciones alarmantes y generalizadoras, pues se trata de acusar al "otro", de denunciarlo en su mala fe; está comprobado que muchos esclavos lograron su libertad precisamente porque guardaban sus partidas bautismales, que si bien el fraude era moneda corriente no era tan sencillo "sustituir" partidas verdaderas por falsas.

${ }^{3}$ De hecho el independentismo cubano alzado en armas desde finales de 1868 no eliminó radicalmente la esclavitud en los campos de Cuba libre hasta diciembre de 1870 y sólo como respuesta a la Ley Moret "maniobra de la clase dominante en Cuba y del poder colonial para encubrir la esclavitud en la Isla y restarle influencia y atracción al movimiento revolucionario" Torres Cuevas, Eduardo y Eusebio Reyes. Ob. Cit. P 241. Para una valoración de las ideas en torno a la esclavitud, abolición y relaciones raciales en las filas del movimiento revolucionario e independentista cubano ver Ferrer, Ada. "Esclavitud, ciudadanía y los límites de la nacionalidad cubana: la guerra de los diez años, 1868-1878", Historia Social, Valencia, 22, 1995, pp. 101-125.
} 
aprovecharse del trabajo de los libertos hasta que cumplieran los 22 años y pagarle medio jornal hasta los $18 .{ }^{4}$ En este panorama de criterios unánimes, que de cierta forma iban conformando una visión que le negaba mérito alguno a la Ley Moret, irrumpieron los juicios sostenidos por Rebecca J. Scott en su tesis de doctorado publicada en $1985 .{ }^{5}$

Quizás el trabajo de la Scott ha sido más valorado por parte de los historiadores económicos y políticos ya que introducía una nueva tesis en el debate sobre las causas de la abolición en Cuba. ${ }^{6}$ En tal sentido los historiadores sociales al parecer no reparan en las múltiples sugerencias que la autora realiza al señalar, en apoyo de su hipótesis, la dinámica capacidad movilizativa de los esclavos a partir de los mecanismos legales existentes. ${ }^{7} \mathrm{Al}$ respecto aprecia que la ley Moret había introducido cambios institucionales y de actitudes que perturbaron el orden social de la esclavitud, ${ }^{8} \sin$ dejar de reconocer que "durante la mayor parte de su vigencia (...) redujo el número total de esclavos, pero liberó relativamente pocos esclavos en edad de trabajar". ${ }^{9}$ En resumen si bien la Ley Moret no tuvo como centro el fin inmediato de la esclavitud sino la creación de un sistema - el patronato - que permitiera a los dueños de esclavos adaptarse a los cambios y asegurar el control de la mano de obra y la reorganización del trabajo, influyó a la larga en el destino de miles de personas.

\footnotetext{
${ }^{4}$ Artículo 7 párrafo segundo. Torres Cuevas, Eduardo y Eusebio Reyes. Ob. Cit. p. 227.

${ }^{5}$ Scott, Rebecca J. Slave Eamncipations in Cuba. The Transition to Free Labor, 1860 199. Princeton: Princeton University Press, 1985. Advertimos que para el presente artículo consultaremos y citaremos la edición cubana del 2001.

${ }^{6}$ Según el profesor José Antonio Piqueras Slave Eamncipations in Cuba. The Transition to Free Labor, 1860-199, es "la obra más renovadora aparecida hasta entonces sobre la sociedad esclavista cubana desde la publicación de El ingenio. La autora opuso una explicación a la desintegración de la esclavitud distinta de la contradicción interna del sistema esclavista en general y de la oposición entre tecnología avanzada y fuerza de trabajo esclava en particular. Scott rechazó una interpretación que entendió determinista y negó la inadaptación del esclavo a los avances técnico-económicos (...)" Ver José A. Piqueras. "El final de la esclavitud en el Caribe". En: José A. Piqueras (comp.) Azúcar y esclavitud en el final del trabajo forzado. Homenaje a M. Moreno Fraginals. Madrid: Fondo de Cultura Económica, 2002. p 23-25.

${ }^{7}$ Scott, Rebecca J. La emancipación de los esclavos en Cuba. La transición al trabajo libre 1860-1899. La Habana: Editorial Caminos, 2001. La autora analiza sobre todo las reclamaciones presentadas a las Juntas Provinciales de Patronato a partir de 1880, pp 189-220.

${ }^{8}$ Ibídem. p. 100.

${ }^{9}$ Ibídem. p. 104.
} 
Al iniciar nuestras indagaciones sobre la familia esclava en Cuba no sospechábamos la importancia que dicha ley tendría para algunas de las personas que se convertían poco a poco en el centro de nuestros estudios. La metodología que proponemos para reconstruir familias de negros y mulatos, libres y esclavos en la feligresía de Bejucal parte de los registros parroquiales, series de bautismos, matrimonios y defunciones y se complementa con otras fuentes documentales y orales. ${ }^{10}$ Fue precisamente en este cruzamiento de fuentes donde acudimos a los archivos de las escribanías de la ciudad, encontrando allí, en medio de cartas de libertad, compra-ventas de esclavos y testamentos, las cesiones de patronato, un tipo de escritura que ponía en evidencia los cambios que la Ley de Vientres Libres introducía en las relaciones entre amos y esclavos y por extensión en la historia familiar de los implicados en estas cesiones, lo que nos permitió encontrarles un justo sentido a las mismas. Sin dicho contexto serían sólo documentos aislados sin más explicación que la presupuesta habilidad o capacidad de resistencia del "esclavo" o la exclamación asombrada del "qué interesante" ante el sorpresivo "hallazgo". ${ }^{11}$

Así entre 1871 - fecha de la primera cesión otorgada en la escribanía de Barona - y 1880 -año en que comenzó a regir en la Isla la Ley de Abolición de la esclavitud creando el sistema de Patronato,$-{ }^{12}$ se pone en circulación

\footnotetext{
${ }^{10}$ Perera Díaz, Aisnara y María de los Ángeles Meriño Fuentes. Esclavitud, Familia y Parroquia en Cuba. Otra mirada desde la microhistoria. Artículo merecedor del Premio Iberoamericano de Ciencias Sociales de la Universidad Nacional Autónoma de México en su tercera convocatoria (2005), de próxima aparición en la Revista Mexicana de Sociología de la UNAM. También Una metodología - desde los registros parroquiales - para la reconstrucción de la familia negra en la Cuba colonial. En Boletim de História Demográfica, São Paulo, Año XI, no 33, setembro de 2004, http://www.brnuede.com/boletinsenha.htm.

${ }^{11}$ Vale decir que en otras localidades de la isla se generó también este tipo de escritura notarial. Cesiones de patronato encontramos en la provincia de La Habana involucrando familias de las feligresías del Santo Cristo de La Salud y San Pedro del Quivicán, esta última con economía cafetalera y por ende mayor población esclava que Bejucal. En Cienfuegos, una ciudad ubicada en la costa sur del país y centro de una rica región plantacionista azucarera Michael Zeuske y Orlando García reportan también dicho documento, pero no realizan un análisis de la misma, claro el objetivo que se proponen en su trabajo difiere en mucho del nuestro, más adelante retomaremos esta referencia.

${ }^{12}$ El texto de dicha ley se puede consultar en Pichardo Hortensia. Documentos para la historia de Cuba. La Habana: Editorial de Ciencias Sociales, 1973, t. I. pp 420-421. Para algunos análisis de dicha ley y sus efectos políticos y económicos remitimos a Scott. Ob. Cit, pp. Blackburn, Robin. "La esclavitud, los propietarios extranjeros de bonos del tesoro y el derrocamiento de la primera República española". En: José A. Piqueras (comp.) Azúcar y esclavitud en el final del trabajo forzado. Homenaje a M. Moreno Fraginals. Madrid: Fondo de Cultura Económica, 2002. pp. 356-363.
} 
este tipo de escrituras que si bien comenzaron teniendo en cuenta sólo a los llamados "párvulos libertos según lo dispuesto por el gobierno"13 terminaron por incluir a todos los antiguos esclavos, ahora llamados patrocinados.

\section{Breve caracterización de un espacio: la ciudad}

San Felipe y Santiago del Bejucal fue uno de los asentamientos ${ }^{14}$ que el Obispo Gerónimo de Nostis y de Valdés alentó como continuador de la estrategia iniciada por su antecesor Diego Evelino de Compostela dirigida a establecer los llamados curatos de montes y por medio de estos estimular el poblamiento interno de la isla de Cuba. Se trataba así de fortalecer el papel de la iglesia en la sociedad criolla, institución que controlaba la recaudación y administración de las rentas decimales con que estaban gravadas la inmensa parte de las explotaciones agrícolas.

E1 9 de mayo de 1714, con treinta familias en su mayoría de origen canario, se fundaba la ciudad. La Real Cédula de erección mencionaba que en el corral del Bejucal, distante siete leguas de La Habana, habían "muchos números de familias, que vivían sin la educación y enseñanza de la doctrina cristiana, por faltarles el trato y comercio político, pues aunque había un cura que cuidadoso solicitaba el bien espiritual de aquellas almas, no lo podía conseguir por estar muy distantes unos de otros". ${ }^{15}$

La estratégica situación geográfica - en la parte más estrecha del Departamento Occidental de la isla - le valió a la pequeña ciudad el que fuera reconocida como centro de una jurisdicción, limitando por el norte con las de Santiago de las Vegas y Santa María del Rosario, por el este con la de Güines, por el sur con el mar Caribe y por el oeste con la jurisdicción de San Antonio Abad o de los Baños. ${ }^{16}$

\footnotetext{
${ }^{13}$ Una de las varias expresiones con que se justificaba en las partidas de bautismo la condición de libres de los niños de madres esclavas nacidos bajo la Ley Moret.

${ }^{14}$ Otras poblaciones fundadas por esa época fueron Santa María del Rosario y Santiago de las Vegas.

${ }^{15}$ Esta queja fue transmitida al rey Felipe V por el Obispo Gerónimo Valdés. Acosta, Manuel Mariano. Memoria sobre la ciudad de San Felipe y Santiago del Bejucal. [Bejucal] JUCEI, SF. p. 6.

${ }^{16}$ Lunar Jiménez, Dania. El desarrollo urbano en Bejucal en los Siglos XVIII y XIX (monografía inédita citada con autorización de la autora).
} 
La fundación de la ciudad ha sido vista como expresión del interés de la iglesia por controlar a un considerable grupo de cultivadores de tabaco, los famosos vegueros, que se iban arraigando como gente independiente y tenían en sus manos la más importante materia prima de la época. Bejucal se proyectaba pues como un centro de influencia gubernamental sobre esta población, hasta el momento dispersa y sin muchos vínculos con el poder que residía en La Habana. El capitán Juan Francisco Núñez de Castilla, propietario de las tierras que sirvieron de asiento para la fundación y dueño a su vez de los molinos de rapé estaba muy interesado en ejercer el control sobre estos cultivadores, ${ }^{17}$ de ahí su fructífera alianza con las autoridades religiosas que mediaron para lograr la real aprobación.

Pero los fundadores no contaban con el fomento del ramo en la región de Vuelta Abajo y la comprobada superior calidad de la hoja que allí se cosechaba, además de que "el verdín para fabricar polvo o rapé decaía visiblemente debido a la preferencia de los consumidores que ya comenzaban a aficionarse al puro y al cigarrillo." 18 por lo que para 1780 había concluido el ciclo tabacalero en la jurisdicción. La tierra explotada por años sólo rendía para el cultivo de forrajes, de modo que la ganadería pasó a ocupar un lugar importante en la economía local. Según Mariano Acosta la cría de reses fue estimulada por "haberse introducido en las mesas el lujo general de la carnes cebadas [que] hicieron cambiar el plan agrícola de los primeros pobladores". ${ }^{19}$

\footnotetext{
${ }^{17}$ Según Mercedes García el primer Marques de San Felipe y Santiago del Bejucal poseía además de los dos ingenios de azúcar, varias caballerías de tierras arrendadas a un grupo de vegueros, de los que cobraba contribución y recibía cantidades de tabaco en rama por ellos cosechados, fue un típico hombre de negocios con inversiones múltiples y "es también ejemplo de los hacendados azucareros que pagaron sus negros al Asiento inglés con tabaco verdín de calidad superior". García Rodríguez, Mercedes. La aventura de fundar ingenios. La refacción azucarera en La Habana del siglo XVIII. La Habana: Editorial de Ciencias Sociales, 2004, p. 31.

${ }^{18}$ Le Riverende Brusone, Julio J. La Habana. (Biografía de una provincia). La Habana: Academia de la Historia de Cuba, Imprenta Siglo XX, 1960. P 236.

${ }^{19}$ Acosta. Ob. Cit. p. 26.
} 
Por otra parte, aunque en tierras de la jurisdicción se establecieron a mediados del siglo XVIII algunos ingenios como el Poveda, ${ }^{20}$ y el Agua Santa, este último de Antonia Pérez de Abreu, esposa de Carlos del Castillo y Sucre, nieto del fundador de la ciudad; o el Jesús María, propiedad del segundo Marques de Cárdenas de Monte Hermoso, no fue el azúcar renglón de importancia en la economía local. Tal es así que, a pesar de la cercanía del puerto habanero, estos ingenios no transitaron con éxito hacia el llamado boom azucarero de fines de aquel siglo. Falta de leña, tierras cansadas y pocos capitales para introducir las mejoras tecnológicas que demandaba la producción a gran escala, fueron las causas de este fracaso.

Así al contrario de lo que sucedió con la región de Güines, Bejucal se mantuvo como un oasis dentro de la expansión azucarera que se produjo por la llanura Habana-Matanzas. ${ }^{21}$ Por lo cual, después de inaugurado en 1837 el primer tramo de ferrocarril Habana-Bejucal, que colocó a Cuba en la vanguardia del empleo de este tipo de transporte, se hizo evidente que las recaudaciones no amortiguaban los gastos de la empresa porque:

“(...) El territorio por donde pasaban las primeras 16 millas del camino de hierro era relativamente poco productivo; únicamente las regiones situadas más al sur de Bejucal podrían suministrar al ferrocarril un volumen de carga realmente satisfactorio (...)". ${ }^{22}$

De esta manera la economía local terminó íntimamente relacionada con el mercado interno de la vecina ciudad de La Habana. Allí se consumían los vegetales y viandas que eran cultivados en los sitios que antes habían sido próspe-

\footnotetext{
${ }^{20}$ Este ingenio le fue donado a la Compañía de Jesús en 1720 a raíz de su establecimiento en la Isla. En 1767 al ser expulsados los jesuitas pasa a ser administrado por la Junta de Temporalidades hasta abril de 1770 cuando fue rematado por la suma de 85011 pesos al teniente coronel Ventura Doral. Sebastián Ignacio de Peñalver, regidor del cabildo habanero entra en posesión del ingenio a fines del siglo XVIII. García Rodríguez Mercedes. Misticismos y capitales. La Compañía de Jesús en la economía habanera del siglo XVIII. La Habana: Editorial de Ciencias Sociales, 2000.

${ }^{21}$ Para un análisis de este proceso ver Moreno Fraginals, Manuel. El Ingenio. 3 t. La Habana: Editorial de Ciencias Sociales, 1978.

${ }^{22}$ Zanetti Lecuona, Oscar y Alejandro García Álvarez. Caminos para el azúcar, La Habana: Editorial de Ciencias Sociales, 1987, p. 38.
} 
ras vegas de tabaco. Aves, cerdos de Oayti, pavos, carneros se destinaban a los mercados y carnicerías de la capital de la isla. La posesión de esclavos fue una vez más el medidor de la bonanza que alcanzaron los sitieros bejucaleños "...es raro el sitio donde no haya negra esclava por lo menos y algunos negritos". ${ }^{23}$

\section{La escribanía de los Barona y el registro de la voz esclava}

Situada a medio camino entre los puertos de La Habana en la costa norte y el de Batabanó en la costa sur, Bejucal era un importante punto en la ruta que unía la enorme provincia habanera, gracias a lo cual en ella funcionaban varios tribunales, primero en las personas de los tenientes gobernadores y de los alcaldes mayores, luego en el juzgado de primera instancia. A dichas justicias debían acudir los habitantes de la jurisdicción de Santiago de las Vegas, y de los partidos de Bauta, Batabanó, el Cano, Wajay, Guatao, Quivicán, Santo Cristo de la Salud, San Antonio de las Vegas e Isla de Pinos. ${ }^{24}$

La primera escribanía pública de cabildo y guerra se estableció en 1803, ${ }^{25}$ pero ya desde 1776 existía una administrada por Carlos Ximenez. Con el tiempo llegaron a tres las oficinas de este tipo, lo cual proporciona una medida de la actividad judicial y de la multitud de negocios que se concertaban en la ciudad. De ello son testimonios los cientos de pliegos encuadernados en gruesos tomos a los que más de una vez se ha acercado el historiador social y económico de la esclavitud, pero no son justamente las compra-ventas de esclavos o de propiedades rurales, las cartas de libertad o las hipotecas, los documentos que una vez más promueven el análisis, sino otros que tras la fórmula notarial dan fe del interés que por la familia tenían los esclavos cubanos.

A pesar de que el siervo no tenía capacidad contractual hay circunstancias en que es posible encontrarlo como usuario de una escribanía. ${ }^{26}$ En estos casos es

\footnotetext{
${ }^{23}$ Acosta. Ob. Cit. p. 26.

${ }^{24}$ De La Pezuela, Jacobo. Diccionario de la Isla de Cuba. Tomo I. Madrid, 1866. p. 158.

${ }^{25}$ Acosta. Ob. Cit. p. 17.

${ }^{26}$ Ya en los protocolos de la ciudad de La Habana a fines del siglo XVI hallamos referencias a esclavos como "contratantes", es decir como usuarios de las escribanías y parte activa de la dinámica económica de la ciudad, ver De Rojas María Teresa. Índice y extractos del Archivo de Protocolos de la Habana, 1578-1585. 3 vols, La Habana: Imprenta Ucar, García y Cía. MCMXCVII. Una muestra de la actividad de los esclavos en negocios cotidianos es una carta orden fechada en 1768 y dirigida por el Gobernador de Santiago de Cuba al Cabo Comandante del poblado minero El Cobre para que hiciese saber a los
} 
indudable que existían acuerdos entre amos y esclavos, los cuales entraban en juego cuando los primeros decidían otorgar licencia o simplemente acompañar a su siervo a la oficina para investir, en su presencia, con "derechos civiles" a quien se encontraba en el escalón más bajo de la pirámide social. Los actos realizados de esta suerte han quedado como preciosos argumentos a favor del papel activo que tenía el esclavo en los marcos de las sociedades coloniales hispanas.

Las evidencias halladas en los protocolos de la Escribanía y Notaría de Justo Barona Díaz de Vivar y luego de su hijo Gaspar Barona Acosta con sede en la pequeña ciudad de Bejucal, ${ }^{27}$ no tratan del uso directo de las leyes, ni de reclamaciones de derechos, reales o supuestos, pero si tenemos en cuenta que una escritura notarial es un documento pre-jurídico, un "constante y vivo trámite entre la ley y la realidad", ${ }^{28}$ en suma que ella "lleva implícito su valor probatorio, por el hecho de que el notario, poseedor de la fe pública del Estado, es quien lo certifica; [que a su vez] está rodeada de solemnidades o formalidades y representa por lo mismo seguridad jurídica", ${ }^{29}$ nos encontramos con personas que conocían el valor único de los actos que inscribían frente a testigos y a un funcionario que daba fe de sus palabras, pero sobre todo con sujetos de derecho ${ }^{30}$ e individuos a los cuales se les re-conocía.

habitantes de dicho pueblo, mediante bando, que se prohibía a los esclavos de Su Majestad hacer o tener contratos y negocios con personas libres "vaxo de la pena que será nulo el q' otorgaren y el que diere algún dinero lo pierda y se castigara los esclavos con el destierro al Castillo del Morro por tanto cuatro años". Archivo Nacional de Cuba en lo adelante (ANC). Correspondencia de los Capitanes Generales. Leg. 23, n. 27.

${ }^{27}$ Sobre esta familia ver Perera Díaz Aisnara y María de los Ángeles Meriño Fuentes. "Yo, el Notario: breve reflexión microhistórica sobre el poder de la escritura, en Boletim de História Demográfica, Año XI, no 33, setembro de 20004, http:// www.brnuede.com/boletinsenha.htm. También Perera Díaz, Aisnara. Juan J. Barona. Crónica de su propio viaje. San Antonio de los Baños: Editorial Unicornio, 2003.

${ }^{28}$ Canellas López, A. "El notariado en España hasta el siglo XIV: Estado de la cuestión", en Notariado público y documento privado: de los orígenes al siglo XIV. Actas del VII Congreso Internacional de Diplomática, I, Valencia: Generalitat Valenciana, Consellería de Cultura, Educació y Ciència, Diputacions d'Alacant, Castelló i Valencia, 1989, p. 101. 29 "Palabra del Notario": Boletín de la Asociación de Notarios y Conservadores de Chile. Santiago de Chile, 2003, ttp://wwwhistoriaeciencia.weblog.com.pt/arquivo/2003_09.html.

${ }^{30}$ Sobre la llamada personalidad legal y moral de los esclavos en las colonias españolas ver la interesante discusión y nueva propuesta que realiza Alejandro de la Fuente al respecto de los planteamientos contenidos en la obra de Frank Tannenbaum Slave and Citizen., De La Fuente se adscribe al concepto, más preciso y objetivo, "de reclamación de derechos para acortar la distancia que media entre la ley como declaración abstracta de derechos y los esclavos como actores sociales con sus propias estrategias y objetivos. 
En la mayoría de estos testimonios descubrimos algo poco frecuente: la subjetividad actuante de esclavos y libres. En ellos están los individuos, como el moreno Cirilo quien a pesar
"de hallarse ciego e imposibilitado de trabajar (...) reclama incesantemente su libertad aunque de hecho disfruta de ella, pues alega (...) el cumpli- miento de dicha promesa para visitar cuando le plazca a sus parientes y amigos y hacer lo demás que puedan las personas libres..."31

Cirilo ha hablado a través de su último dueño, Don Manuel Oramas, quien no tuvo otra opción que cumplir con la voluntad de su difunta esposa Doña Evarista Cabrera. Para aquel, por su avanzada edad, la libertad tenía un sentido concreto: poder visitar a parientes y amigos sin solicitar permiso o licencia por escrito. Sin dudas no confiaba en una situación de facto que podía variar con la muerte de Oramas y su traspaso a los herederos de este, los cuales no tendrían reparo en venderlo. Cirilo conocía el valor argumental del documento escrito, por ello exigía "el papel".

Desde luego, dichos documentos también demuestran que es posible encontrar tras el Amo a la persona dispuesta a negociar sus intereses. Desde la viuda que se nos presenta como una bondadosa señora, que casi siempre concede libertades condicionadas, hasta el pragmático hombre de negocios que prefiere ganarse la lealtad de sus siervos no por medio de castigos, aunque no renuncie a ellos, sino mediante pequeñas concesiones. Pues sin dudas la estabilidad del sistema esclavista estaba no sólo en los mecanismos represivos y de coacción violenta sino que descansaba en buena medida en cientos de miles de acuerdos individuales y negociaciones ocultas entre amos y esclavos.

\footnotetext{
"En vez de asumir que el derecho positivo dotaba a los esclavos de una personalidad "moral", como afirmaba Tannenbaum, sostengo que fueron los esclavos, al establecer demandas y presionar por el logro de beneficios, quienes dieron un significado social concreto a los derechos abstractos regulados por el derecho positivo. Mediante esas interacciones con las autoridades y los jueces coloniales, los esclavos actuaban (y eran percibidos) como sujetos jurídicos con una capacidad legal limitada". De La Fuente, Alejandro. "Slave Law and Claims-Making in Cuba: the Tannenbaum debate revisited". Law and History Review 22;2 (2004), 339-69.
}

${ }^{31}$ ANC. Escribanía de Justo Barona, Bejucal. 1866. Carta de libertad, folio 402. 
Es conocido que la vida del siervo fue reglamentada y sometida al más estricto control. El derecho al matrimonio es el único de carácter civil, junto con el de coartarse, que se le reconoció ampliamente por los diversos reglamentos elaborados con ese fin entre 1789 y $1842 .{ }^{32}$ Aunque se trató de proteger a la familia, al prohibirse la venta de niños menores de tres años y la separación de los esposos, ${ }^{33}$ por lo general estos derechos digamos mínimos no fueron respetados por muchos dueños. Los esclavos tuvieron que batallar duramente por la unidad de su parentela, con un por ciento de éxito que no es posible precisar, aunque en muchos de los casos estudiados hemos visto la reunificación después de la libertad.

\section{Otra mirada a la Ley de Vientres Libres de 1870.}

La ley Moret o de Vientres Libres del 4 de julio de 1870 había dispuesto la libertad de todos los niños nacidos de madre esclava, ${ }^{34}$ con la condición de que aquellos quedasen en poder de los amos en calidad de patrocinados hasta la edad de 22 años, después de cumplidos los dieciocho años y hasta el cese del patronato su trabajo sería remunerado mediante un corto jornal, la mitad del que ganaba un hombre libre. ${ }^{35}$ El patronato podía se transmitido "por todos los medios conocidos en derecho" y renunciado "por justas causas". En tal caso se privilegiaba a los padres, legítimos o naturales, y de condición libre, a los cuales se les concedía el derecho a reivindicar el patronato de sus hijos pagando al patrono los gastos hechos en beneficio del liberto. ${ }^{36}$

\footnotetext{
${ }^{32}$ Ortíz, Fernando. Los negros esclavos. La Habana: Editorial de Ciencias Sociales, 1987. Real Cédula e instrucción circular a Indias sobre la educación, trato y ocupación de los esclavos, Capítulo VII Matrimonios de esclavos. p. 411 y Reglamento de esclavos de 1842 o Código negro hispano-cubano, artículos 34, 35 y 36 sobre coartación p. 447.

${ }^{33}$ Según el Reglamento de 1842 en el caso de que marido y mujer fueran de amos diferentes el amo del esposo debía comprar a la esposa y a los hijos menores de tres años. Ibídem. P 446.

${ }^{34}$ Artículo 1. "Todos los hijos de madres esclavas que nazcan después de la publicación de esta ley son declarados libres". Artículo 2. Todos los esclavos nacidos desde el 17 de septiembre de 1868 hasta la publicación de esta ley son adquiridos por el Estado mediante el pago a sus dueños de la cantidad de 125 pesetas. Torres Cuevas y Reyes. Ob. Cit. p. 227.

${ }^{35}$ Ibidem. Artículo 8, p. 228.

${ }^{36}$ Ibídem. Artículo 11.
} 
Sobrepasando el lugar común de calificar a la Ley de Vientres libres como una continuación solapada de la esclavitud, coincidimos con Rebecca J. Scott cuando sugiere que la ley (...) "Proveía una palanca - débil, frágil, rudimentaria - que permitía a algunos esclavos ejercer influencia sobre su condición o la de sus parientes." (... ${ }^{37}$ Sin dudas la ley significó un cambio de perspectivas para muchas familias que habían estado toda su vida en esclavitud. Este "párvulo ingenuo" era el primer miembro de la familia que disfrutaba teóricamente de la libertad, lo que convertía a la ley en un campo de negociación entre los dueños, ahora llamados patronos, y sus padres. De este modo las acciones de padres, abuelos y otros parientes fueron decisivas para que la Ley Moret adquiriera un significado concreto más allá de sus imperfecciones y sus carencias, y aún del hecho cierto de que no eliminaba en Cuba la esclavitud. Así las habilidades, conocimientos y relaciones de los esclavos - la puesta en acción de toda una experiencia social acumulada que no podemos desdeñar - se conjugaron una vez más para alcanzar la libertad.

La publicación de la ley en Cuba fue dilatada hasta septiembre de 1870. Si bien conocemos el efecto que esta causó entre los círculos de propietarios, hacendados y comerciantes españoles, también sobre las críticas y señalamientos publicados en varios órganos de prensa en Madrid, ${ }^{38}$ lamentablemente sabemos muy poco de la recensión de esta en el país, sobre todo entre los esclavos, sin dudas la parte más interesada en su aplicación.

La acción combinada de los hacendados propietarios de esclavos de la Isla y de las autoridades coloniales retardaron aún más la entrada efectiva de la ley en el terreno de la práctica cotidiana. Así el reglamento para su aplicación fue implementado hacia finales de 1872, cercenando en algunos aspectos el alcance de la ley. ${ }^{39} \mathrm{El}$ reglamento del cinco de agosto del propio año creaba las llamadas Juntas Protectoras de Libertos con la función de velar por los derechos de todos los que la ley Moret había declarado libres. ${ }^{40}$ Entre sus atribuciones destacamos la referida a la cesión que los patronos pudieran hacer de sus derechos:

\footnotetext{
${ }^{37}$ Scott. Ob. Cit. pp. 104-105.

${ }^{38}$ Barcia. Ob. Cit. p. 143.

${ }^{39}$ Scott. Ob. Cit. p. 99.

${ }^{40}$ Para ampliar sobre las atribuciones y demás funciones de las Juntas ver Reglamento de la ley de 4 de julio de 1870 sobre la esclavitud en Cuba, fechado el 5 de agosto de 1873. En Torres Cuevas y Reyes [24] pp. 230-241.
} 
"admitiendo las que se funden en causas que las Juntas consideren justas y probadas, sin que las renuncias tengan jamás por resultado la separación de hijo menor de 14 años de su madre sierva. Esta separación tampoco será permitida en los casos de transmisión del patronato". ${ }^{41}$

Las cesiones de patronato son una excelente expresión de cómo se recepcionó e interpretó la ley Moret, que no sólo incluía las libertades por edad o las ventas de madres con sus hijos patrocinados, los que a su vez no fueron "vendidos junto a sus madres como un premio extra para el comprador" ${ }^{2}$, lo cual sugieren nuestros colegas Michael Zeuske y Orlando García Martínez. Cuando un dueño vendía a una madre y a sus hijos nacidos con posterioridad a septiembre de 1868 no violaba la ley, algo que también insinúa Barcia Zequeira al referirse a las transgresiones que se desprenden de los anuncios de ventas de "negras con sus 'crías' desde pocos meses de nacidas" casos no hacía más que transmitir por "justa causa de derecho" el patronato de estos niños, legalmente libres pero sometidos a su tutela. Estas ventas y cesiones de patronato eran en todo caso preferibles a la separación de madre e hijos tal como ocurría antes de la promulgación de la ley cuando era lícito, a pesar de lo reglamentado, la venta de infantes de muy corta edad. ${ }^{44}$

\footnotetext{
${ }^{41}$ Ibídem p. 232.

${ }^{42}$ Zeuske, Michael y Orlando García Martínez. "Notarios y esclavos en Cuba (siglo XIX)". En Debates y Perspectivas, Cuadernos de Historia y Ciencias Sociales, Madrid: Fundación Mapfre-Tavera, N. 4, Diciembre de 2004, p 144. Quizás para sostener esta afirmación habría que comparar los precios de ventas de mujeres jóvenes en edad reproductiva sin hijos y con hijos. En el caso de que se detectara alguna variación significativa de los precios es posible admitir entonces que efectivamente los hijos fueran un premio, una "contra o ñapa" (como se decía en la época) que el vendedor daba de más y como estímulo al comprador, mientras tanto es arriesgado adelantar este tipo de juicio. Según un amplio estudio del mercado cubano de esclavos, los precios de la mujeres jóvenes vendidas en La Habana en las décadas del 50 y del 60, alcanzaron como promedio los 788 pesos. Después de la Ley Moret los precios cayeron en un 40\%, situándose en los 475 pesos. Lamentablemente los autores de dicho estudio no explican como influyó en el precio la disposición en torno a los hijos. Bergard, Laird, Fe Iglesias García y María del Carmen Barcia. The Cuban Slave Market. 1700-1880. Cambridge, N.Y: Cambridge University Press. 1995. Versión en CDR p. 104.

${ }^{43}$ Barcia. Ob. Cit. pp. 145 y 157.

${ }^{44}$ Abundan los ejemplos de ventas de niños. Es sabido que algunos amos, sobre todo los de pocos recursos, tenían a sus siervas como productoras de esclavos y procedían a la venta de los hijos de estas como la manera más rápida de obtener algún dinero en efectivo o para pagar deudas. Esta interesante cuestión aguarda por un estudio más detallado. Ci-
} 
Hacía mayo de 1871 encontramos la primera referencia concreta a la ley Moret en un documento que el escribano bejucaleño asienta erróneamente como de "libertad", cuando se trataba de una cesión de patronato que a su vez podía muy bien ocultar la venta de la párvula libre. Don José Leandro de Castañeda y Don Casimiro Amable vecinos del pueblo de La Salud se habían puesto de acuerdo sobre el destino de la pequeña Nicasia de cuatro meses de nacida,

“(...) que según lo dispuesto por el Superior Gobierno es libre de toda esclavitud y bajo este concepto fue asentada su partida bautismal pero como según la misma Superior disposición tiene el otorgante el derecho de retenerla en su servicio hasta que cumpla dieciocho años bajo las condiciones prescriptas en la ley del particular como patrono de la liberta siéndole gravoso continuar criando a dicha negrita ha acordado con el segundo cedérsela como desde luego se la cede para que usando del referido derecho de patronato la conserve en su poder hasta la oportunidad que marca la ley del particular bajo las precisas condiciones que la misma prescribe en la forma que pudiera hacerlo el primer compareciente sin responsabilidad de ningún género pues queda totalmente libre y exento de carga alguna sobre el particular todo lo que vende y reasume el segundo que se constituye a mantener y criar dicha negrita como su patrono en la forma ordenada por el Superior Gobierno sin que ahora ni en ningún tiempo pueda reclamar cosa alguna a Castañeda ni contradecir el tenor de esta escritura que ambos ratifican en la más bastante forma obligando a la primera sus bienes según derecho... ${ }^{45}$

Al Castañeda - o al escribano - no obstante se le "escapa" la palabra vende, - sin dudas la verdadera intención del acto que realizaba ante el escribano - después

tamos este ejemplo pues pudimos reconstruir el destino de este infante y apreciar el esfuerzo del abuelo para reunir a la familia: En 21 de octubre de 1841 el moreno libre José del Rosario Peñalver, natural y vecino de Quivicán compra el negrito Sixto, de 2 años de edad, a Don Pedro Pérez, vecino del partido de Batabanó. El Pérez a su vez lo había comprado a Don Juan Lansa cinco meses antes, su valor 100 pesos. ANC. Escribanía de José de la Luz Portela, 1841, folios 206-206v. En 1861 Sixto Montier es coartado en 800 pesos por su abuelo José Montier, quien además coarta a la madre de Sixto, Arcadia Montier y paga la libertad de dos nietos nacidos en 1858 y 1860. Para las coartaciones ver ANC. Escribanía de José Ortega 1861. Folios 25 y 25 vuelta, para las libertades ANC. Escribanía de Justo Barona 1858, escritura de libertad fechada el 28 de julio de 1858 y Escribanía de José Ortega 1861. Folio 24 vuelta-25.

${ }^{45}$ ANC. Escribanía de Justo Barona. 1871, folio 282 vuelto. 
de haber declarado el propósito de ceder sus atribuciones. Así Amable asume los derechos y deberes de patrono, sobre todo los de aprovecharse, llegado el caso, de los servicios de Nicasia. Creemos que esta escritura está a medio camino entre una venta, a pesar de que no se hace mención a cantidad de dinero y la cesión de patronato tal y como la encontramos meses después en la misma escribanía.

Detengámonos brevemente en la fórmula de una escritura de cesión de patronato. Esta refleja los datos que usualmente recogen todas las escrituras: lugar y fecha, identidad de los comparecientes, los que hacen declaración de poseer a los niños en virtud de haber nacido de sus esclavas, seguidamente se remiten a la ley y exponen las razones que le llevan al acto de cesión, a continuación la contraparte previamente identificada acepta la cesión, asumiendo las responsabilidades del caso.

En las escrituras de 1875 encontramos más formalidad. La entrada en vigor de la ley del notariado influye en este cambio. Quizás también el hecho de que a Justo Barona le haya sucedido en la administración de la escribanía, ahora transformada en Notaría, su hijo Gaspar Barona Acosta, joven con más conocimientos de las nuevas leyes y obligado a introducir uniformidad en las escrituras que asiduamente extendía en el despacho familiar.

De este modo el proceso hacia una fórmula notarial más completa y abarcadora de los términos legales que tiene como referente se ha completado. Ahora el notario es más exacto en la identificación de las partes, a los nombres y apellidos se agrega la naturaleza y vecindario, edad, oficio, la declaración de estar en el pleno goce de sus derechos civiles, si se está al corriente de las contribuciones o si por cuestión de pobreza no se es contribuyente. Parte importante de la escritura es aquella donde se detallan las obligaciones que asume la persona que recibe el patronato comprometiéndose "a mantenerlos, vestirlos, calzarlos, educarlos, enseñándole a trabajar e inculcándoles buenas materias de moralidad en sujeción a lo que en particular tiene dispuesto el Superior Gobierno y a lo que en adelante tengan a bien ordenar con referencia a dichos libertos" ${ }^{46}$ o esta otra que además"se obliga a curarlo de sus enfermedades (...) y todo lo demás consiguiente conforme a las superiores disposiciones que rigen la materia". ${ }^{47}$ Ambas declaraciones son reelaboradas a partir del artículo

\footnotetext{
${ }^{46}$ ANC. Protocolo de Gaspar Barona. 1875. Escritura de cesión de patronato, 30 de enero de 1875. Folio 198.

${ }^{47}$ ANC. Protocolo de Gaspar Barona. 1875. Escritura de cesión de patronato, 13 de abril de 1875.
} 
7 de la ley Moret que trataba las obligaciones del patrono respecto a sus clientes: "vestirlos, asistirlos en sus enfermedades y darle la enseñanza primaria y educación necesaria para ejercer un arte o un oficio". ${ }^{48}$

Tenemos la oportunidad de comparar las cesiones de patronato de Bejucal con la que trascriben en su interesante artículo Zeuske y García Martínez, otorgada en la ciudad de Cienfuegos en noviembre de 1875. La fórmula empleada por el notario cienfueguero hace que esta escritura tenga más puntos de contacto con una libertad graciosa que con las cesiones de patronato tal y como se entendía esta acción según la Ley Moret. Como hemos visto el notario Barona Acosta crea su propia fórmula donde recoge el espíritu de la ley en cuanto a los deberes del patrono con sus patrocinados menores de edad, mientras que la escritura otorgada por la señora Concepción Bacallao de López a favor de su esclava Juliana, se limita a justificar la acción de gracia donde no mediaba pago "en mérito de los buenos servicios de la citada madre Juliana Padilla," y a consignar que "se aparta y separa de la propiedad, posesión y demás acciones que a dicha Tomasa del Carmen había y tenia", 49 eso sí esta cesión tiene la peculiaridad de que es la madre, esclava aún, quien se convierte en patrona de su hija de tres años, lo cual es reafirmación de lo que venimos diciendo de los espacios de negociación que permiten que un esclavo adquiera personalidad jurídica plena, pues en su calidad de patrona la Padilla estaba obligada a cumplir con ciertos requisitos impuestos por la Ley de Vientres libres, que eran los mismos que le correspondían como madre en el caso de que fuera libre.

Las escrituras de cesión de patronato que hemos localizado - fechadas entre 1871 y 1875 - involucran a abuelas, madrinas u otra personas íntimamente ligadas a las esclavas y a sus hijos. ${ }^{50}$ (Ver Anexo II y III) En ellas se ponen de relieve la eficacia y funcionabilidad de las redes de parentesco consanguíneo y por afinidad. Por otra parte es muy posible que sean la culminación de meses de negociaciones, presiones y exigencias, donde al parecer no intervienen ni el Procurador Síndico ni la Junta Protectora de Libertos, es decir sin otro poder

\footnotetext{
${ }^{48}$ Torres Cuevas y Reyes [24] p 227.

${ }^{49}$ Zeuske y García Martínez. Ob. Cit. p.163.

${ }^{50}$ De las cinco escrituras comprendidas en ese lapso de tiempo cuatro tienen como receptoras a africanas, dos abuelas y dos madrinas de bautismo, lo cual habla muy a favor de la capacidad de movilización de estas mujeres.
} 
mediador que la propia gestión ante la autoridad señorial. ${ }^{51}$ Significativamente, en ninguna se menciona el dinero pero no descartamos que los familiares tuvieran que hacer pagos a los patronos para lograr de estos la ansiada entrega. ${ }^{52}$

\section{Niños libres, madres esclavas: los límites de una nueva esperanza}

El documento que comentamos es precisamente una de estas cesiones de patronato pero se distingue por un detalle especial: la intervención que en el mismo tiene la madre.(Ver Anexo I) Son protagonistas de este, la familia que desde 1860 habían constituido José María de la Candelaria López Viera y María Isabel Baldomera Coll. Esclavos de amos diferentes habían procreado siete hijos entre 1861 y 1871 , pero en 1872 se produjo un giro en la vida de la madre y de los pequeños.

Don José Coll y Rigot, natural de Cataluña, pequeño propietario rural, vecino del cuartón Buenaventura, jurisdicción de Bejucal, decidió que sus días de sitiero habían concluido. Desde 1829 mantuvo un sitio de caballería y media de tierras - ubicado en Aguas Verdes - con su trabajo personal, auxiliado por muy pocos esclavos, a saber un criollo llamado Pablo, otro congo de nombre José Damián y la criolla Juana María, más los cinco hijos de estos nacidos entre 1838 y $1851 .{ }^{53}$ De ellos fue María Isabel Baldomera, la única que le daría más esclavos, los siete niños nacidos hasta 1871.

\footnotetext{
${ }^{51}$ Lamentablemente no tenemos conocimiento de las apelaciones presentadas en las diversas Juntas Protectoras que nos permitan hacer una distinción entre las que trataban de reclamaciones de esta índole y aquellas que analiza Scott. [24] pp. 106-119.

${ }^{52}$ Quizás este haya sido el caso de la morena libre natural de África María del Rosario Rodríguez y del sitiero Don Martín Isla, vecino de La Salud quien enfrentaba una grave situación financiera. Isla reconoce que "siéndole algo gravoso continuar al cuidado de dichas párvulas ha acordado ceder el derecho de patronato que le compete a favor de la otra compareciente abuela de aquellas". ANC. Protocolo de Gaspar Barona. 1875. Tomo I. escritura 103 de cesión de patronato 22 de febrero de 1875, folio 306. Isla había vendido en 1868 a otra nieta de María del Rosario, "una mulatica nombrada María Eufemia criolla de año y medio" por la suma de 100 pesos. ANC. Escribanía de Justo Barona. 1868. folio 219. Como ya no podía vender a las niñas libertas es posible que existiera un acuerdo donde el Isla exigió y recibió un "rescate" por estas y así resarcirse de los "daños y perjuicios" que la ley Moret le infligía .

${ }^{53}$ En su testamento Coll declaró que estos esclavos, más el sitio, una yunta de bueyes y un caballo fueron los bienes que había llevado al matrimonio, ANC. Notaria de Gaspar Barona Acosta. 1876. Folio 8.
} 
El viejo Coll para hacerse de capital enajena a cuatro de los niños y a la madre en enero de 1872. Por Baldomera y sus hijos Vidal, José Ramón Quintín, Florencia y Pedro López Coll, percibe la suma de 2800 pesos, de la cual emplea 1800 en la compra de dos casas contiguas de mampostería y tejas, situadas en la calle Sacristía. ${ }^{54}$ Pero a pesar de que dispersa a la parentela pues dos de los compradores son del pueblo de La Salud, tiene un gesto de consideración para con la familia. El mismo día en que formaliza las ventas en la escribanía de Justo Barona, otorga escritura de cesión de patronato de la pequeña Cecilia:

“(...) de su espontánea voluntad y en que está conforme la expuesta su madre cede, renuncia y transfiere dho (dicho) derecho de patronato a favor de la parda libre Serapia González a quien en el particular pone en el propio lugar y grado del otorgante pero con expresa sujeción a lo dispuesto sobre el particular por el Superior Gobierno y a lo que en lo adelante pueda ordenarse respecto a los libertos y estando presente D José López mediante el cargo de Serapia González aceptó a su favor está escritura y sus términos"(...) ${ }^{55}$

Coll expresa que realiza la cesión espontáneamente. En verdad podía haber entregado a la pequeña Cecilia al comprador de Baldomera, pero quizás circunstancias muy especiales lo obligaron a este acto. José López, que representa a la González, era el dueño del padre de Cecilia y de sus tíos y abuelos paternos. Un propietario que se mostró particularmente generoso con la familia de una de las tías de Cecilia llamada Merced, al concederles la libertad graciosa a ella y a sus hijos habidos con el moreno libre Benigno Contreras. López interpuso su prestigio, solvencia económica y moral a favor de la familia de su esclavo.

Dejar a la pequeña al cuidado de Serapia González, natural de Bejucal y dedicada a "lavar y planchar para la calle", es posible que haya sido una decisión conjunta de los padres esclavos. Sabemos que entre esta y la parentela de José existían vínculos que se tradujeron en relaciones de compadrazgo. ${ }^{56}$ La parda había accedido a la libertad en 1869 y tenía una sola hija también

\footnotetext{
${ }^{54}$ En 1876 Coll adeudaba a varias personas la cantidad de 717 pesos, entre sus acreedores estaban dos esclavos.

${ }^{55}$ ANC. Escribanía de Justo Barona 1872. Escritura de cesión a la ley del patronato, folio 51.

${ }^{56}$ En 1877 y 1878 Serapia González fue madrina de los dos últimos hijos de los Contreras-López.
} 
liberta, por lo tanto estaba en condiciones de acoger a una niña y asumir su atención. Algo que no podía hacer la tía Merced López, pues en enero de 1872 se encontraba cuidando a una hija nacida en agosto del año anterior. Es decir la familia Contreras-López tenía problemas concretos que enfrentar como conseguir una casa propia donde vivir en la medida en que fueron accediendo a la libertad..$^{57}$

Por otra parte esta acción evidencia la relación de cercanía entre libres y esclavos, que fue más usual y dinámica de lo que a veces se acepta. Muchos de los que como Serapia habían accedido a la libertad no se apartaban de sus consiervos mediante la defendida línea divisoria de la movilidad social. Los libres participaban con suma frecuencia en el apadrinamiento de los hijos de sus excompañeros de cautiverio, en un simultaneo movimiento de aproximación que prestigiaba a ambas partes. En el caso estudiado la "línea del color" tampoco separó a la González y a los López-Coll, la primera descrita como "parda" a pesar de que su madre era denominada como arará, lo cual es indicio de que su padre era un blanco "no conocido" y los segundos clasificados como "morenos". Quizás el origen africano de ambas familias sea la base de este encuentro. ${ }^{58}$

También es digna de ser destacada la proximidad entre esclavos calificados como “de campo," los López-Coll en los sitios de labor de sus respectivos dueños, que aunque próximos a la ciudad de seguro para trasladarse a esta debían contar con la correspondiente licencia de los amos, y una lavandera, Serapia, que tenía en la ciudad su escenario laboral. Por supuesto que en una urbe pequeña, como lo era Bejucal, los límites entre lo urbano y lo rural se confunden. No obstante vale la observación como prueba de que muchas veces es falsa la barrera que parece separar a los esclavos de la ciudad de los del campo.

En la escritura se expresa la conformidad de Baldomera para que su hija quedase al amparo de Serapia, una cuestión que además de cubrir las formas legales denota que la ley Moret introducía en algunos casos el consentimiento

\footnotetext{
${ }^{57}$ De hecho en agosto de 1873 a poco de nacida la sexta hija, Merced paga 100 pesos a su ex amo por una "casita con el frente y una culata de mampostería y lo demás de tabla, con el techo de tejas la que fabricó a sus expensas hace tres años tiene seis varas de frente y veinticuatro de fondo". ANC. Escribanía de Justo Barona. 1873. Venta real de casa, Folio 698. El matrimonio llegó a tener nueve hijos, lo cuales quedaron huérfanos de madre en 1879.

${ }^{58}$ Hasta el presente en Cuba no se ha estudiado con sistematicidad la cuestión del padrinazgo, dicho estudio debería tener como fuente obligada los registros parroquiales. Al respecto hemos dedicado al tema un capítulo de nuestro libro aún inédito Esclavitud, Familia y Parroquia en Cuba. Otra mirada desde la microhistoria.
} 
paterno sobre el destino de los hijos libres. Al menos es la única escritura de su tipo donde consta el acuerdo materno. Ella no está presente directamente en el acto, como no lo está Serapia, sin embargo es evidente que ambas tienen voluntades y deseos propios que se ponen de manifiesto cuando llegamos al conocimiento de los detalles que entrelazan las vidas de todas estas personas.

Mucha confianza habría de tener la pareja en la red de familiares y amigos para no llevar consigo a su niña al pueblo de La Salud, dejándola en un mundo de personas libres al que por otra parte se integraría el padre meses después. ${ }^{59}$ Baldomera y sus otros hijos seguirían siendo, por un tiempo que nadie podía calcular, esclavos dependientes de los vaivenes de las fortunas de sus amos, expuestos a otras ventas pues estaban "sujetos a servir" tal y como expresaba la monótona fórmula que justificaba las transacciones de personas. Así gracias a los vínculos del parentesco por afinidad, Cecilia permaneció al abrigo de "gente amiga" en un entorno de personas libres. Sus hermanos corrieron peor suerte. Quintín, murió a los dos años de haber sido vendido. Le sobrevivió Pedro, al igual que Florencia, enajenada a la ciudad de La Habana y Vidal. ${ }^{60}$

El documento analizado es sólo una muestra de las posibilidades de construir historias de vidas a través de la explotación intensiva de las evidencias que las escrituras y documentos notariales nos brindan. El derecho a tener relaciones familiares contra todos los imponderables nos presenta a sus creadores, esclavos y libres, personas analfabetas e iletradas, como seres apegados a normas y valores éticos que de cierta manera guían sus actos. Nos interesa ahondar en el poder de trasformación que estas escrituras o el mismo acto de otorgarlas, ejercieron en las vidas de estas personas, buscar las "transgresiones" que lograron introducir en los documentos, por lo general espacios esquemáticos y regidos por la "fórmula" creada por el escribano o por la ley, de modo que nos lleven a un mejor entendimiento de los aspectos sociales del fenómeno esclavitud y sus implicaciones en las vidas de quienes se impusieron a la desesperanza y la humillación.

\footnotetext{
${ }^{59}$ López liberó graciosamente a todos sus esclavos en 1873, días antes de dictar su segundo testamento. Eran más de doce, todos con relaciones de parentesco entre sí, es decir madres, padres, hijos y hermanos, africanos y criollos. Quizás al no tener herederos forzosos pudo disponer con más libertad de sus bienes.

${ }^{60}$ Los López-Coll tuvieron un total de ocho hijos. Además de los cuatro que se mencionan en la cesión, estaban Lorenza nacida en 1867 y a la cual la viuda de Coll vende en 1877, a un vecino de la ciudad de La Habana; Tecla nacida en 1872 pero muerta ese mismo año de tétano infantil, y Natividad nacida en 1874, cuya descendencia llega hasta la actualidad. Sabemos que una vez libres, Florencia y Vidal, retornan a la ciudad.
} 


\section{Anexo I}

Archivo Nacional de Cuba. Escribanía de Justo Barona 1872. Folio 51.

\section{Cesión a ley de patronato}

En la ciudad de Bejucal en veinte de enero de mil ochocientos setenta y dos ante mí el Eno y testigos compareció D José Coll, mayor de edad, vecino del cuartón de Buenaventura a quien doy fe conozco y dijo que conserva en su poder a ley de patronato una negrita nombrada Cecilia de tres años de edad hija de otra que fue su esclava Baldomera criolla que he enajenado en esa fecha a favor de D Ramón de León que por la razón explicada la referida negrita Cecilia está comprendida en la ley vigente que trata de la libertad de esclavos y mediante el derecho de patronato que aquella le asiste el otorgante de su espontánea voluntad y en que está conforme la expuesta su madre cede, renuncia y transfiere dho derecho de patronato a favor de la parda libre Serapia González a quien en el particular pone en el propio lugar y grado del otorgante pero con expresa sujeción a lo dispuesto sobre el particular por el Superior Gobierno y a lo que en lo adelante pueda ordenarse respecto a los libertos y estando presente D José López mediante el cargo de Serapia González acepto a su favor está escritura y sus términos se da por recibido de la negrita Cecilia y ofrece cumplir exactamente con las disposiciones que rigen y puedan regir en lo adelante respecto del particular y por lo que a cada uno toca guardar y cumplir obligan sus bienes presentes y futuros conforme a dho, en cuyo testimonio así lo otorgaron firmó el compareciente D José Coll y por el aceptante que expresó no saber de su ruego lo hizo uno de los testigos que lo fueron D Pedro Acevedo, D Luis Ortega y D Francisco de Paula González, vecinos presentes... 


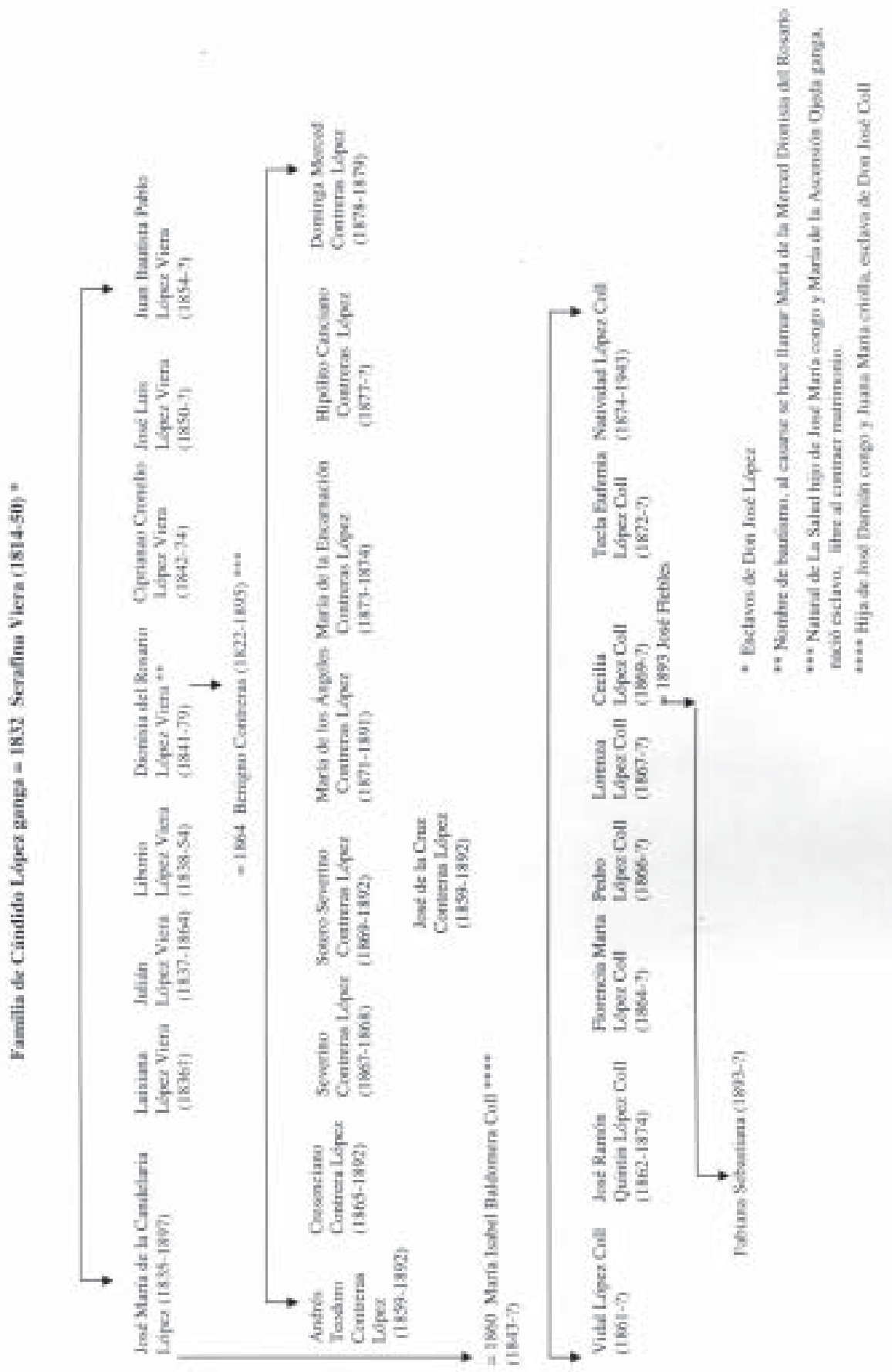




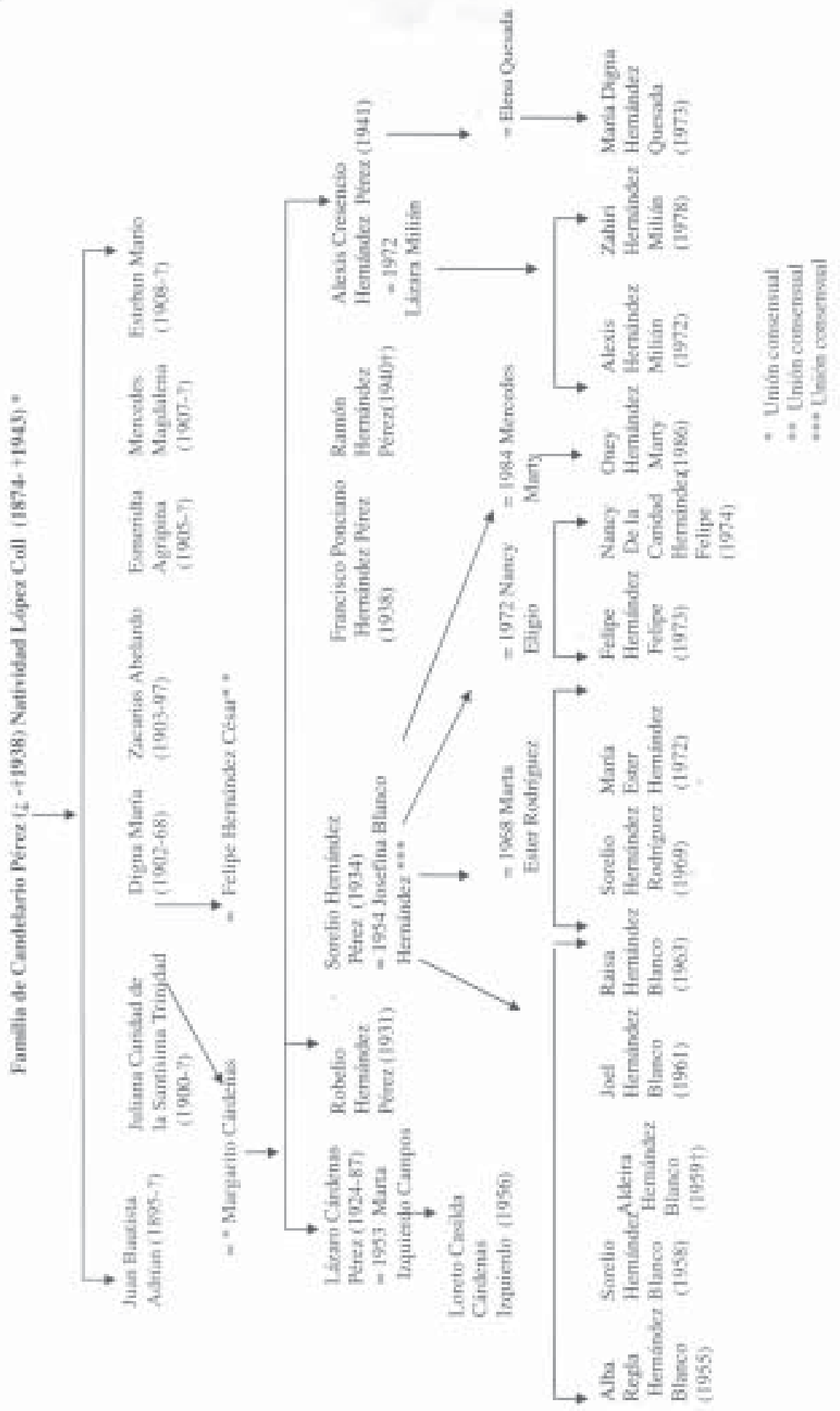




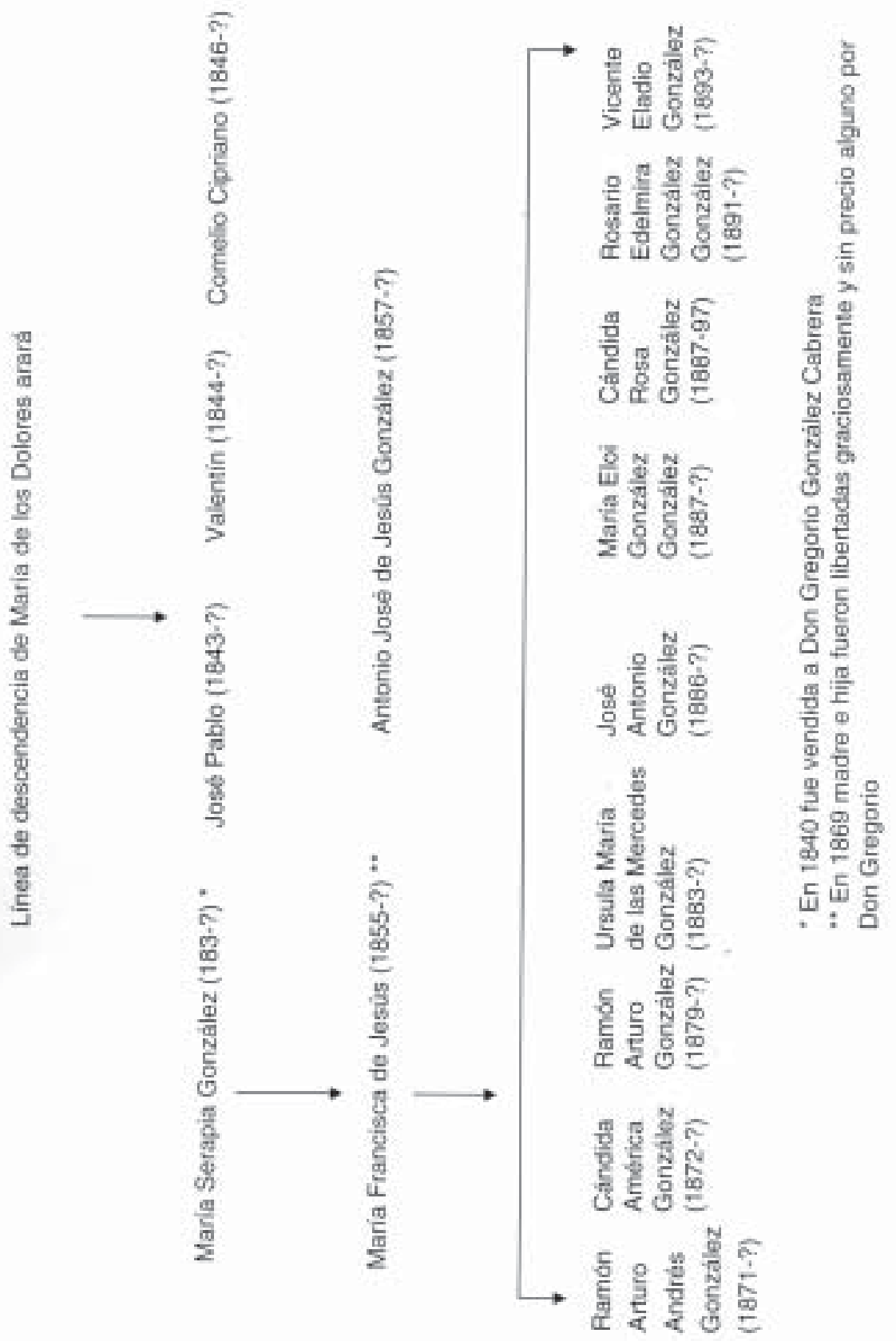




\section{Anexo II}

\section{Cesión a ley de patronato}

En la ciudad de Bejucal en dieciséis de abril de mil ochocientos setenta y tres ante mí el Eno y testigos compareció Da Merced Díaz viuda mayor de edad de este vecindario a quien doy fe conozco y dijo que le pertenece a ley de patronato una pardita nombrada Carlota de dos años de edad hija de otra su esclava llamada María de Regla, que ha convenido con Regina Caballero ${ }^{61}$ su madrina de este mismo vecindario cederle bajo el mismo orden de patronato y con las mismas sujeciones y demás requisitos que previene dicha ley y las que pueda en el caso dictar el Superior Gobierno a la referida parda Carlota para que la posea y utilice en su servicio en el orden y forma que pudiera hacerlo la compareciente y conforme a las disposiciones indicadas separándose en consecuencia de cualesquiera acción y derecho que pudiera asistirle y a que todo lo cede y traspasa en la indicada Regina Caballero y sin retribución de parte de esta de ninguna clase y presente la referida Regina aceptó a su favor esta escritura y recibe la parda Carlota en el orden y término en que le va cedida y se obliga a cumplir lo que ordena la ley de la materia en cuyo testimonio así lo dijeron y firmó la expuesta Da Merced Díaz no haciéndolo Regina Caballero por expresar no saber a su ruego lo hizo uno de los testigos que lo fueron D Luis Ortega, D Francisco de Paula González y D Francisco Correa, vecinos presentes.

Nota: En esta fecha di testimonio de esta escritura en un pliego del sello de pobre. Bejucal julio primero de mil ochocientos setenta y tres.

\footnotetext{
${ }^{61}$ Regina Caballero era lucumí, fue esclava en el ingenio Santa Ana de Aguiar. El abuelo de la ahijada de Regina también era un lucumí de nombre Arcadio. Quizás este hecho haya influido en ambos eventos, es decir en que ella fuera la madrina de Carlota y que a su vez aceptara ser su patrona. Archivo de la Iglesia Parroquial de Ascenso de San Felipe y Santiago del Bejucal (AIPASFSB). Libro 6, 7 y 8 de Bautismos de Pardos y Morenos de la Iglesia Parroquial de Ascenso de San Felipe y Santiago del Bejucal.
} 


\section{Anexo III}

\section{Cesión de patronato Escritura 103}

En la ciudad de Bejucal a veintidós de febrero de mil ochocientos setenta y cinco ante mí D Gaspar Barona y Acosta, Eno Notario Público con fija residencia en esta dha ciudad y de los testigos que se dirán comparecieron de una parte D Martín Isla, que dijo ser natural y vecino del partido de La Salud, de estado viudo, labrador y de sesenta años de edad y de la otra la morena libre María del Rosario Rodríguez, natural de África, ${ }^{62}$ de este vecindario, viuda y mayor de sesenta años de edad a quien conozco de que doy fe y de que aseguran estar al corriente el primero en el pago de la contribución según recibo que ha presentado y se le devuelve y la segunda que juró solemnemente no poseer bienes de ninguna clase y asegurando hallarse en el pleno goce de sus derechos civiles y con la capacidad legal necesaria para este otorgamiento dijeron que el primero tiene a su abrigo y cuidado en calidad de patrono dos negritas nombradas María Closefula de cuatro años de edad y Anastasia de nueve meses de nacida, criollas, hijas de su esclava también criolla llamada Ramona González cuyas párvulas pertenecen a la clase de libertas según la disposición del Superior Gobierno y siéndole algo gravoso continuar al cuidado de dichas párvulas ha acordado ceder el derecho de patronato que le compete a favor de la otra compareciente abuela de aquellas quedando excento el otorgante de toda responsabilidad pues la compareciente María del Rosario Rodríguez se hace cargo de las referidas párvulas María Closefula y Anastasia en calidad de patrona obligándose a mantenerlas, vestirlas, calzarlas, educarlas, enseñándole a trabajar e inculcándoles buenas materias de moralidad en sujeción a la que en particular tiene dispuesto el Superior Gobierno y a lo que en adelante tengan a bien ordenar con referencia a dichos libertos sin

\footnotetext{
${ }^{62}$ María del Rosario Rodríguez, era gangá, estuvo esclavizada desde 1820 en tierras del Quivicán donde procreó una familia de ocho hijos con un carabalí de nombre Eduardo, cuando asume el patronato de estas nietas tenía algunos biznietos. AIPASFSB. Libros 6, 7, 8 y 9 de Bautismos de indios, pardos y morenos de la Iglesia Parroquial de San Pedro del Quivicán. Ramona Norbeta era la menor de todos sus hijos, nacida en La Salud en 1844. AIPASFSB. Libro 3 Bautismos de pardos y morenos de la Iglesia del Santo Cristo de La Salud. 7 de julio de 1844.
} 
que en manera alguna pueda ser molestado ni perjudicado el exponente a cuyo efecto le entrega las expresadas negritas bajo cuyo concepto acepta esta escritura la otra compareciente obligándose al cumplimiento de todas las cargas que son consiguientes como tal patrona sin responsabilidad alguna por parte de Isla y en esa virtud se da por entregada de las indicadas negritas y por lo que a cada uno toca guardar y cumplir obligan sus bienes conforme a derecho, así lo dijeron y otorgaron siendo testigos D Pedro Fernández Corvo y D José Genaro Valdés, de este vecindario y sin excepción para serlo como lo juran, a los cuales doy fe conozco, fueron enterados los otorgantes y testigos por mí el notario que podían leer por sí esta escritura, lo que rehusaron por lo cual procedí a su instancia a la lectura íntegra de la misma en su solo acto y en su contenido se ratificaron los primeros, no firmaron porque expresaron no saber y lo hicieron por D Martín Isla uno de los testigos y por María del Rosario Rodríguez D Francisco de Paula González, por ante mí que también doy fe.(Firma de todos los comparecientes y la del notario) 